\title{
NEAR-TERM TECHNOLOGIES FOR IMPROVING AUTOMOTIVE EFFICIENCY: A REVIEW AND UPDATE
}

\author{
John DeCicco, Senior Associate, American Council for an Energy-Efficient Economy, Washington, DC. \\ Marc Ross, Professor of Physics, University of Michigan, Ann Arbor.
}

\begin{abstract}
This paper reviews the potential for improving the fuel economy of conventional, spark-ignition engine automobiles through optimized use of production technologies and near-term refinements thereof. The analysis is presented at three levels of technical certainty, ranging from technologies already in use to newer technologies facing technical constraints (such as emissions control problems) which may inhibit widespread use. Estimates are aggregated to project a range of U.S. new car fleet average fuel economy levels achievable given roughly 10 years of lead time. Estimates are verified by simulation analysis of an average car, which permits accounting for interactions between drivetrain and tractive load measures. Technology cost estimates are compared to fuel savings to determine likely cost-effective levels of improvement, which are found to range from $39 \mathrm{mpg}$ to $51 \mathrm{mpg}$ depending on technology certainty level. A vehicle stock turnover model is used to project the reductions in gasoline consumption and associated emissions that would follow if these fuel economy levels are achieved.
\end{abstract}

\section{Introduction}

Understanding the technical opportunities for improving new vehicle fuel economy underpins the development of balanced policies for controlling light vehicle fuel use in the United States. We focus here on potential improvements in the near-term, defined as a roughly 10-year horizon according to considerations discussed in the report on which this paper is based. 1 Previous studies identified potential new car fleet averages ranging from $28 \mathrm{mpg}$ (no improvement over recent levels) to $45 \mathrm{mpg} .{ }^{2}$ Disagreements can be traced to differing assumptions about the benefits, costs, applicability, and marketability of the technologies considered. Earlier studies by one of the authors provided the upper end of the range. 3,4 Other assessments include federally sponsored studies by Energy and Environmental Analysis, Inc. (EEA), 5-7 and studies by auto industry consultants such as SRI. ${ }^{8}$ The recent National Research Council study drew mainly on these preexisting sources. The technologies included for the previously published estimates are five or more years old; newer technologies and further refinements of existing ones are not fully included.

Our analysis considers more widespread use of technologies already in production plus the introduction of emerging technologies. The review is organized under major headings representing the engine, transmission, and tractive load aspects of vehicle design. An aggregate analysis of fleetwide fuel economy improvement builds on the technology status of the new car fleet in a base year, 1990, for which average vehicle size and performance are maintained. Examination of contemporary auto industry product cycles, development times, and rates of technology change, leads to an estimate that 8-11 years are needed to achieve the efficiency improvements identified here. ${ }^{1}$ To both capture the integrated nature of design and check our results, we also apply an engineering model to analyze potential improvements for a typical vehicle.

Reflecting the uncertainties surrounding new applications of technology, results are developed at three levels of technical certainty:

Level 1 technologies are already in production in at least one mass market vehicle worldwide and face no technical risk in that they are fully demonstrated and available.

Level 2 technologies are ready for commercialization and face no engineering constraints (such as emissions control considerations) which inhibit their use in production vehicles, but entail some risk because of limited production experience.

Level 3 technologies are in advanced stages of development but face some technical constraints before they can be used in production vehicles.

In this context, technical risk is interpreted as the risk that a technology cannot be put into widespread use within the time horizon identified here at acceptably low cost (full production scale average cost). For options better characterized by degree of design refinement, such as aerodynamic improvements or weight reduction, the certainty levels are interpreted differently; they are successively less conservative regarding the degree of improvement.

\section{Technology Review}

In this review, engine, transmission, and load-reduction technologies are treated separately for convenience. In reality, these aspects of design are closely related. Fuel economy (mpg) values and benefit estimates are given for the EPA composite city/highway cycle (unadjusted for on-road shortfall). Benefit estimates for each technology reviewed here are listed in Table 1. Length restrictions prevent full discussion and literature citation in this paper; analytic details and a list of over 160 references are provided in our report. ${ }^{1}$

\section{Engine Technologies}

A number of refinements to the conventional four-stroke spark-ignition engine have reached production and near-commercial status over the past decade. These Level 1 technologies include higher compression ratio, fuel injection, overhead camshafts, four valves per cylinder, roller cam followers, and other friction reduction techniques. These refinements can increase engine specific power (ratio of horsepower to cubic inch displacement), which permits decreased engine displacement for a given level of vehicle performance. However, many have been applied for increasing vehicle performance as well as fuel economy, with greater gains in performance in recent years. The mpg benefits of these technologies are well understood; the estimates listed in Table 1 are drawn from previously published sources. ${ }^{2,7,9}$

Copyright (c) by the American Council for an Energy-Efficient Economy (ACEEE).

Published by the American Institute of Aeronautics and Astronautics, Inc., with permission. 
Variable Valve Control (VVC) has multiple benefits long known to automotive engineers. In conventional engines, the timing and lift (extent of opening) of intake and exhausts valves are fixed functions of crank angle, so that the same timing and lift are used at all engine speeds and loads. VVC mechanisms permit valve positions to be controlled depending on operating conditions, thereby permitting a more optimal management of induction and exhaust processes. The benefits of VVC include better low-end torque, lower emissions, reduced pumping losses, lower idle speed, and higher fuel economy. In the past, the challenge of developing a VVC mechanism that could be cost-effectively implemented on production models inhibited much use of this technology. Widespread application is now possible in light of ongoing advances in design and electronic control capabilities, along with realization that there are VVC mechanisms which, while not fully variable, largely capture the benefits. Based on a literature review as well as fuel economy and horsepower ratings observed in recent models, we estimate a $12 \% \mathrm{mpg}$ benefit for VVC and classify it at Level 1 certainty.

Variable displacement is another form of variable engine control. A variable displacement engine deactivates some of its cylinders at low loads, reserving them for high load conditions. The result can be a considerable improvement in part-load efficiency and overall fuel economy. Effecting variable displacement by selective valve deactuation can be thought of as an extension of variable valve control. Mitsubishi has a $1.6 l$ variable displacement engine, called the MIVEC, for use in Japanese models and under consideration for the U.S. market. This engine can shut down two of its four cylinders by disengaging their valve cams at low loads below 3400 RPM but can deliver $175 \mathrm{hp}$ (109 hp/liter) with all cylinders firing. Published estimates of the mpg benefit of variable displacement span a range of $16 \%-50 \%$. However, these estimates do not fully control for interactions with other drivetrain technologies. Our analysis suggests a net mpg benefit of $5 \%$ (classified at certainty Level 2) if variable displacement is implemented along with the other technologies considered here.

Boosting, or use of a turbocharger or supercharger to pressurize cylinder intake air, is typically applied to enhance performance. However, "optimal redesigns of downsized gas engines with such forced induction systems can demonstrate potential [mpg] gains up to $8 \%$ " compared to larger, naturally aspirated engines. ${ }^{8}$ A turbocharger can create an emissions control problem because it comes between the exhaust manifold and the catalyst, cooling the exhaust and delaying catalyst light-off. This could be remedied by catalyst pre-heating, which adds cost, or perhaps by careful design. Superchargers would not have this problem but are less efficient than turbochargers because they do not recover exhaust energy. We estimate that boosting offers a $5 \% \mathrm{mpg}$ benefit at certainty Levels 1-2 and estimate an $8 \%$ benefit only at Level 3 because of the emissions control challenge.

Idle off, or engine "stop-start," allows the engine to be turned off when no power is demanded, for example, when a vehicle is stopped, braking, or coasting. This technology has been demonstrated by Volkswagen, with reported fuel savings of $20 \%-30 \%$ (unspecified baseline). ${ }^{10}$ Analyzing idle-off relative to a specified baseline vehicle and in combination with other technologies for improving part-load efficiency yields an estimated mpg benefit of $11 \% .4$ Our re-analysis reduces the estimate to $6 \%$ after adjusting for other aggressive measures which cut part-load losses.
Lean burn refers to using air:fuel ratios much greater than the stoichiometric ratio (roughly 15:1 for gasoline). Conventional four-stroke spark ignition engines normally operate with a stoichiometric mixture. Diesel engines operate lean, as do advanced two-stroke spark ignition engines. Advantages of lean burn include reduced pumping loss, improved thermal efficiency, and potentially reduced $\mathrm{HC}$ and $\mathrm{CO}$ emissions. A disadvantage is the difficulty of catalytic No reduction under lean conditions. Lean-burn vehicles have not yet been certified to the $0.4 \mathrm{~g} / \mathrm{mi} \mathrm{NO} \mathrm{N}_{x}$ level being phased-in as the new U.S. standard over 1994-96. Research on lean catalysts has been underway since the early 1980s. Recent focus has been on copper-zeolite catalysts; the main problem appears to be achieving sufficient catalyst durability. The contribution of lean burn to the overall fuel economy improvement demonstrated in the Civic VX is about $10 \%$, which we use as our estimate for the implementation of lean burn alone. We classify lean burn at Level 3 because of the uncertainty regarding $\mathrm{NO}_{x}$ emissions.

Two-stroke engines are getting renewed attention, particularly since Orbital Engine Company's 1989 announcement of an advanced two-stroke that could potentially meet stringent emissions standards. Two-stroke engines offer higher specific power and higher low-end torque, allowing a smaller displacement two-stroke to replace a larger four-stroke engine. The engine downsizing potential and inherently lean-burn design imply substantial fuel economy gains. However, two-stroke engines are also challenged by the most stringent U.S. $\mathrm{NO}_{\mathrm{x}}$ standards. Advanced two-strokes, using fuel injection, forced scavenging, electronic control, and an oxidizing catalyst, have shown test results approaching some of the stronger emissions standards. ${ }^{11}$ Some of the two-stroke's fuel economy benefits overlap with those achievable in an advanced multivalve four-stroke engine with VVC and lean burn. However, the two-stroke is likely to provide these benefits at lower cost. We estimate a net mpg benefit of $10 \%$, classified at Level 3 because of the emissions concerns.

Diesel (compression ignition)engines offer a potentially large efficiency improvement over a gasoline-powered spark ignition engine because of their much higher compression ratios, high part-load efficiency, and amenability to turbocharging. The main hurdle in the U.S. market is the difficulty of simultaneously meeting $\mathrm{NO}_{\mathrm{x}}$ standards of $0.4 \mathrm{~g} / \mathrm{mi}$ along with low particulate standards. Since we have not found research results that would support the use of petroleum-fueled diesel engines in non-hybrid vehicles, we exclude diesels from our estimates of potential fuel economy improvement, even at certainty Level 3. However, the active European efforts to pursue clean diesel technology using advanced direct injection designs and emissions controls with low-sulfur fuel suggest that diesels could re-emerge as an option for the U.S. market.

\section{Transmission Improvements}

Maximizing the time an engine operates at its peak efficiency, near wide-open throttle, requires an optimal synchronization of transmission and engine. The engine should operate at low speed and near open throttle as much as possible while maintaining driveability (responsiveness to changes in power requirements). Two aspects of transmission design are most relevant here. One is the number of gears and their ratios. The "N/v" ratio (e.g., RPM per mph) corresponds to the number of engine revolutions per distance travelled in top gear. Fewer engine revolutions per mile means less energy lost to engine friction. The other design 
aspect is the shift schedule, which matches transmission operation with engine operation. Basic transmission refinements are adding gears in either manual or automatic transmissions, and torque converter lockup in automatics. Estimated mpg benefits are $5 \%$ for increasing to five gears and $3 \%$ for the lockup. ${ }^{2}$

Continuously Variable Transmissions (CVTs) of various designs have been under development for some time and are in production on models such as the Subaru Justy. A CVT can allow an engine to operate at the lowest possible RPM under a given load and rev the engine up when more power is needed. We adopt an estimate of $6 \%$ higher fuel economy than a 3 -speed automatic ${ }^{7}$ including a $2 \%$ downward adjustment to account for overlap with VVC but excluding the effects of optimized transmission control. CVTs would be used in place of 5-speed automatics in vehicles for which they offer lower cost.

Optimized transmission control, also termed "aggressive transmission management," keeps an engine operating at as low an RPM as possible subject to driveability constraints. Optimization is implemented electronically, through sensing throttle position and other parameters as needed to synchronize the transmission with the engine and provide smooth shifting. If engine displacement is reduced to take advantage of technologies that increase specific output, the engine will operate more frequently near wide-open throttle. Optimized transmission control is thus a strategy for facilitating low-RPM, open throttle operation at low and moderate loads while providing downshifts to access greater power when needed. The estimated mpg benefit is $9 \%$ for optimized control of a 5-speed automatic transmission. ${ }^{4}$ Manual transmission gearing and shift points can also be optimized for greater efficiency. Manual transmission optimization yields an estimated mpg benefit of $11 \%$, from conversion to 5-speed gearboxes (6-speeds would help further) and use of taller gearing and shift indicator lights.

\section{Load Reduction}

The preceding drivetrain improvements increase the efficiency with which energy is delivered for overcoming vehicle loads. Vehicle loads include the three tractive loads--aerodynamic drag, tire rolling resistance, and braking (inertial) losses--plus accessory loads, such as heating, air conditioning, lighting, and power steering. Load reduction has a beneficial ripple effect on fuel economy since drivetrain components can be made smaller, resulting in lower loads from the mass and size of the engine and transmission themselves. Dramatic fuel economy increases (fivefold or more) are theoretically possible with an "ultralight strategy" involving radical redesign of vehicles for extremely low tractive loads. ${ }^{12}$ Here we examine only the more modest load reductions obtainable by moving the fleet toward the best current practice in conventional vehicle design.

The first column of Table 2 shows fuel energy utilization over a composite city/highway driving cycle for a typical vehicle. Our example is the 1991 Ford Taurus, a mid-sized vehicle with a fuel economy of $27 \mathrm{mpg}$, close to the recent new car fleet average. The breakdown of fuel energy sinks lists the major vehicle loads and engine friction, which is shown separately for powered and idling (including non-powered deceleration) modes. Thermodynamic losses of fuel combustion are not broken out here, but distributed through all load and friction energy sinks. Vehicle accessories use about $5 \%$ of the energy. We estimate a $30 \%$ reduction in accessory loads, implying a $1.7 \%$ fuel economy benefit, plus a $0.5 \%$ benefit from improved lubricants. 4 The discussion below focuses on the major sources of load reduction: lower tire rolling resistance, lower aerodynamic drag, and lower vehicle mass.

The ratio of tire rolling resistance to its load (the weight borne by the tire) is termed the coefficient of rolling resistance, $C_{R}$. $C_{R}$ can be decreased by a variety of tire design and construction features and ongoing improvements have been made over the years. EEA estimates average new car tire $C_{R}$ at $1.1 \%$ in recent years and projects a decrease to $0.85 \%$ by 2001.6 Some tire makers have recently announced products with $20 \%-35 \%$ lower $C_{R}$ (baseline unspecified) without compromising traction and handling. Even greater $C_{R}$ reductions can result from new materials, such as plastic injection molded tires. The 65 psi tires developed by Goodyear for the GM Impact electric vehicle have a $C_{R}$ of $0.48 \%$, but GM hedges on whether and when such a level might be broadly applicable throughout the fleet. As with many other automotive design features, lower tire rolling resistance can involve a trade-off between performance and efficiency. Our review suggests near-term new fleet average $C_{R}$ values of $0.85 \%, 0.75 \%$, and $0.65 \%$ at certainty Levels $1-3$, implying mpg benefits of $3.4 \%, 4.8 \%$, and $6.1 \%$, respectively.

Aerodynamic drag is proportional to the frontal area of a vehicle and to a shape-dependent drag coefficient, $C_{D^{*}}$. Improved aerodynamics concentrates on streamlining, e.g., more rounded, gently tapered contours and sloped windshields, in order to reduce the $C_{D}$. Average new car $C_{D}$ in 1990 was $0.352( \pm 0.037)$, with $25 \%$ of models having a $\mathrm{C}_{\mathrm{D}}$ of 0.33 or less (authors' analysis of data from EEA). At least 13 models with $C_{D}$ below 0.30 have been in mass production since 1987. Currently, the most streamlined production model is the GM Opel Calibra, with a $C_{D}$ of 0.26 since 1990. EEA projects a new fleet $C_{D}$ average of about 0.23 as attainable by $2010 .{ }^{6}$ Our review suggests near-term new fleet average $C_{D}$ values of $0.28,0.27$, and 0.26 at certainty Levels $1-3$, implying mpg benefits of $3.3 \%, 3.8 \%$, and $4.3 \%$, respectively.

Reducing vehicle mass is a key approach for improving fuel economy, particularly during urban travel, where frequent braking dissipates much of a vehicle's kinetic energy. A $1 \%$ mass reduction yields a $0.66 \% \mathrm{mpg}$ improvement if engine displacement is reduced so as to hold acceleration ability constant. ${ }^{6}$ Since this analysis excludes vehicle downsizing, we examine opportunities to reduce mass through materials substitution and improved design and manufacturing techniques. Previous studies have estimated a near-term potential for $10 \%$ mass reduction from materials substitution. 2,6

The ability to reduce mass through better design is reflected by the current variability in weight-to-volume ratios for contemporary cars. Most of weight variation in the fleet is within, rather than among, volume-based car classes. A potential curb weight reduction of $20 \%$ can be inferred by assuming evolution of the fleet toward the better half of current achievement in terms of weight vs. interior volume. ${ }^{1}$ This $20 \%$ reduction does not include the potential $10 \%$ reduction from materials substitution, implying a total potential reduction of $30 \%$. We assign a range of $10 \%-30 \%$ mass reduction to certainty Levels $1-3$, respectively. We apply these percent reductions to curb weight, working from the 1990 new car average of $2880 \mathrm{lbs},{ }^{13}$ and then make an upward adjustment of $100 \mathrm{lbs}$ to account for safety and emissions standards. The result is estimated mpg benefits of $4 \%$ to $16 \%$ at certainty Levels 1 to 3 , respectively. Given the possibility of an "ultralight" approach utilizing advanced 
composites and radical redesign that can halve the car mass at constant size, 12 we believe that potential mass reduction of $10 \%$ to $30 \%$ is conservative in light of late $20^{\text {th }}$ century technological capabilities.

\section{Fleetwide Aggregation}

To project the potential increase in fleet average fuel economy, the mpg benefits are multiplied by the potential increases in fleetwide utilization relative to the 1990 base year. Estimates are adjusted to reflect interactions and potential overlaps among the technologies. The benefit estimates for some technologies were lowered because of their order on the list, reflecting our judgement of which technology is likely to be applied sooner because of better cost-effectiveness or recent trends. For example, we gave variable valve control (VVC) priority over variable displacement and idle-off. The latter two would have higher benefits if implemented without VVC, but VVC is more likely to be implemented first. The mpg benefit for some transmission technologies is reduced by $2 \%$ to account for interaction with engine measures that also improve part-load efficiency. Utilization increases are given at two levels, denoted "High" and "Full." Further details on utilization rates and adjustments are provided in our report. The adequacy of our procedure for avoiding double counting was verified by simulation analyses of representative vehicles.

Table 3 summarizes our estimation of aggregate new car mpg improvement potential, with subtotals by category (engine, transmission, load reduction). Properly adjusted engine and transmission improvements are additive. Load reduction combines with these drivetrain improvements in a multiplicative fashion. The "Optimal Total" at the bottom of Table 3 is formed by multiplying the summed load reduction benefits by the summed drivetrain benefits. The resulting estimates range from $40 \mathrm{mpg}$ to $56 \mathrm{mpg}$, or a $40 \%$ to $100 \%$ improvement over the $27.8 \mathrm{mpg}$ base. Differences among technology certainty levels are larger than those due to assumed utilization rates. Level 3 is $44 \%$ higher (relative to the $27.8 \mathrm{mpg}$ base) than Level 1 under the High utilization assumptions. The Full utilization cases are about $10 \%$ higher than the corresponding High utilization cases. The jump from Level 1 to Level 2 is due to improvements in all three categories (engine, transmission, load). The jump from Level 2 to Level 3 is due to further engine improvements and load reduction. Generally, about half of the overall potential improvement is from engine technology, about three-tenths is from load reduction, and the remainder is from transmission improvement.

\section{Physical Analysis for an Average Car}

To examine how the technologies reviewed here might apply to a particular car, we performed a simulation analysis using an engineering model of engine fuel consumption and vehicle loads. ${ }^{14,15}$ In detailed form, the model has eight parameters for vehicle characteristics and seven parameters for driving cycle characteristics. The following simplified representation suffices for this discussion:

$$
\left.P_{f}=k V<N\right\rangle+\frac{1}{\eta}\left\langle P_{0}\right\rangle
$$

Average fuel use rate, $P_{f}$ is modeled in terms of engine speed, $N$, and brake power output, $\boldsymbol{P}_{b}$. Key engine parameters are displacement, $V$, specific friction, $k$ (engine friction per revolution and unit displacement), and thermal efficiency, $\eta$. Vehicle parameters include mass, $C_{D}$, and $C_{R}$; along with driving cycle characteristics, these combine to determine $P_{b}$. This model generally fits EPA Test Car List mpg values within $\pm 5 \%$ using public data on vehicle characteristics.

The modeled base vehicle energy use breakdown is shown in the first two columns of Table 2. Projecting fuel economy improvement involves estimating the effect of each technology improvement on the model's parameters. Load reduction decreases the required brake power $P_{b}$. Mechanical efficiency improvement involves reduction of total engine friction, decreasing the $k V<N>$ product. A large cut in engine friction is obtained by downsizing the engine (enabled by technologies which enhance specific power) and making compensatory transmission/driveline changes to provide higher power when needed while maintaining low average engine speeds. Applying a set of Level 2 technologies yields the energy use reduction factors shown in Table 2.

Multiplying base vehicle fuel energy use by the reduction factors yields the reduced energy consumption shown under the improved vehicle columns of Table 2. Average vehicle loads are reduced $26 \%$ (the 0.739 reduction factor shown in brackets). The compression ratio (CR) increase obtained with the more advanced engine implies a $2.5 \%$ thermal efficiency improvement (relative, not absolute), which is applied to the subtotal of vehicle loads. The net engine friction reduction factor of 0.44 (shown in brackets) is the product of reduction factors of 0.53 for displacement and 0.83 for specific friction. The total reduction of energy consumption is $1196 \mathrm{~kJ} / \mathrm{km}$, breaking down as $338 \mathrm{~kJ} / \mathrm{km}(28 \%)$ from load reduction and $858 \mathrm{~kJ} / \mathrm{km}$ (72\%) from drivetrain improvements resulting in higher engine efficiency. The improved "Taurus" thus has a composite fuel economy of $47 \mathrm{mpg}$, a $75 \%$ increase above the $27 \mathrm{mpg}$ rating of the 1991 Taurus. A similar analysis using a more detailed model of engine friction yields essentially the same result. ${ }^{15}$ This vehicle-specific analysis thus verifies the results of the Level 2 aggregate analysis summarized in Table 3.

A number of issues arise in considering what such an improved car would be like to drive. Outward appearance would be little different than that of the 1991 model. Size would be unchanged but the shape would be more aerodynamic ( $a C_{D}$ of 0.27 instead of 0.33 ). Average engine speed would be unchanged. However, having a 4- rather than 6-cylinder engine might raise noise and vibration concerns; we believe that these could be addressed by careful design. More noticeable would be the downshift delays, which are typically one-half second or less. These are a common experience in some 4-cylinder vehicles with automatic transmissions and would become more common in the improved vehicle, which would use a downshift strategy to access power with the smaller engine. Thus, the "feel" of driving will be different, although shift transitions can be smoothed out using the electronic controls.

\section{Cost/Benefit Analysis}

Accurately estimating the cost of improving fuel economy is difficult because of limitations in publicly available data and costing methodologies. Our technology cost estimates, listed in Table 1, are derived from our review 
of previously published information. These estimates represent the incremental costs of improved, mature technology averaged over a total period of production. The applicability of these cost estimates depends on assumptions regarding industry product cycles and other factors which affect the economics of motor vehicle production. ${ }^{1}$

The technology benefit, cost, and utilization estimates were used to construct supply curves of potential fuel economy improvement and gasoline savings. For summary estimates, we used an average of the High and Full utilization rates at each of the three technical certainty levels. Figure 1(a) plots potential new car fleet average fuel economy against the Cost of Conserved Energy (CCE). The CCE is based on the ratio of incremental technology cost to fuel savings discounted at a $5 \%$ real rate over a 12 -year vehicle life. It is an index of cost-effectiveness from the perspective of all consumers (all owners over the car lifetime rather than only the new car buyer). Technologies are cost-effective if their CCE is lower than the future price of gasoline expected over the life of the improved vehicles, assumed to be $\$ 1.65 /$ gallon (1993\$) in 2010. The results are estimated cost-effective new car fleet averages of $39 \mathrm{mpg}, 46 \mathrm{mpg}$, and $51 \mathrm{mpg}$, or $41 \%, 65 \%$, and $82 \%$ higher than the 1990 base year level, at certainty Levels $1-3$, respectively. The corresponding average per-car retail price increases are $\$ 540$, $\$ 770$, and $\$ 840$ (1993\$). Thus, the estimated costs of fuel economy improvement are quite modest, ranging 3\%-5\% of average new car price. These estimates are corroborated by the historical experience of past mpg improvements, for which retrospective analyses have found cost increases of roughly $5 \%$ of average new car price.

Figure 1(b) shows the cost of nationwide gasoline savings in 2010 for new vehicle fuel economy improvements achieved by 2005 . This graph assumes proportionate efficiency improvements in light trucks and expresses the CCE as a crude oil price equivalent, based on a relation between oil price and retail gasoline price. Level 2 assumptions imply that gasoline savings of 2.8 million barrels per day (Mbd) can be obtained at a cost of $\$ 33$ per barrel. These savings would amount to a one-third cut in U.S. light vehicle fuel consumption, which is otherwise expected to reach $9 \mathrm{Mbd}$ by 2010 . Sixty percent of the savings are from improvements in passenger car fuel economy. The remainder are from proportionate improvements in light truck fuel economy, which we believe are similarly feasible and cost-effective although a similar analysis is yet to be done for light trucks.

Higher fuel economy also reduces carbon dioxide and hydrocarbon (HC) emissions. Improving new light vehicle mpg 65\% (Level 2) by 2005 would cut greenhouse gas emissions by 140 million metric tons per year $\left(\mathrm{MT}_{\mathrm{c}} / \mathrm{yr}\right)$ in 2010 (full fuel cycle $\mathrm{CO}_{2}$-equivalent emissions expressed on a carbon mass basis). This is an $8 \%$ reduction in total U.S. greenhouse gas emissions otherwise projected for 2010. A substantial portion of evaporative (non-tailpipe) HC emissions are proportional to the amount of gasoline consumed. 16 Achieving the Level 2 mpg improvements by 2005 would cut $\mathrm{HC}$ emissions by 500,000 tons per year in 2010, a cut larger than that expected from the U.S. Tier I emissions standards. The cost of these emissions reductions is zero for mpg improvements having a CCE up to the avoided cost of gasoline $(\$ 1.65 / \mathrm{gal})$. For mpg improvements below the fully cost-effective level, emissions reductions are achieved at net savings.

\section{Conclusion}

Our review of the automotive engineering literature reveals a wide array of available and near-commercial technologies which can be applied to improve fuel economy over the next decade. Many refinements implemented to varying degrees provide a large range of potential improvement. Higher levels involve greater uncertainty, but at an intermediate level, uncertainties are reduced because there are multiple options. Thus, there is a variety of technical options for improving the fleet to our estimated mid-range level (46 mpg new car average) given adequate lead time. While the application of any one technology might involve uncertainty, a similar degree of efficiency improvement can be achieved through other technologies. Different approaches are likely to be taken by different manufacturers.

The report on which this paper is based also addresses the relationship between investments needed to improve fuel economy and issues such as market risks and competitive factors in the auto industry. The issue of fuel economy improvement is largely one of how the industry's substantial, competition-driven capabilities are directed. In the absence of market signals or public policies for improving fuel economy, the industry's talents have been directed toward greater performance, luxury, and product differentiation, some of these coming at the expense of fuel economy. We find no inherent reason why the industry's capabilities could not otherwise be channeled, with little change in risk or cost, given government policies to motivate fleetwide fuel economy improvement. With adequate lead time and balanced policies, conventional vehicle fuel economy improvements of $40 \%-80 \%$ can be achieved in roughly ten years at modest per-vehicle cost. The result would be substantial benefits of fuel savings, reduced oil imports, and reduced environmental damage.

\section{References}

1. DeCicco, J., and M. Ross. An Updated Assessment of the Near-Term Potential for Improving Automotive Fuel Economy. American Council for an Energy-Efficient Economy, Washington, DC, 1993. Available from ACEEE Publications, 2140 Shattuck Avenue, Suite 202, Berkeley, CA 94704, 510-549-9914.

2. OTA. Improving Automobile Fuel Economy: New Standards, New Approaches. Report OTA-E-504, Office of Technology Assessment, U.S. Congress, Wasington, DC, 1991.

3. Ledbetter, M., and M. Ross. Supply curves of conserved energy for automobiles. Proc. 25th IECEC, Reno, NV, 1990.

4. Ross, M., M. Ledbetter, and F. An. Options for Reducing Oil Use by Light Vehicles: an Analysis of Technologies and Policy. American Council for an Energy-Efficient Economy, Washington, DC, 1991.

5. Greene, D.L., and K.G. Duleep. Costs and benefits of automotive fuel economy improvement: a partial analysis. Transportation Research 27A(3):217-235, 1993.

6. EEA. An Assessment of Potential Passenger Car Fuel Economy Objectives for 2010. Report for U.S. Environmental Protection Agency by Energy and Environmental Analysis, Arlington, VA, July 1991. 
7. EEA. Documentation of Attributes of Technologies to Improve Automotive Fuel Economy. Report for U.S. Department of Energy by Energy and Environmental Analysis, Arlington, VA, October 1991.

8. SRI. Potential for Improved Fuel Economy in Passenger Cars and Light Trucks. Report for Motor Vehicle Manufacturers Association by SRI International, Melno Park, CA, 1991.

9. NRC. Automotive Fuel Economy: How Far Should We Go? Report of the Committee on Fuel Economy of Automobiles and Light Trucks. National Research Council, Washington, DC, 1992.

10. Seiffert, U., and P. Walzer. Automobile Technology of the Future. Society of Automotive Engineers (SAE), Warrendale, PA, 1991.

11. Hellman, K.H., G.K. Piotrowski, and R.M. Schaefer. Evaluation of Research Prototype Vehicles equipped with Direct Injection Two-Stroke Cycle Engines. Report EPA/AA/CTAB/92-01, U.S. Environmental Protection
Agency, Ann Arbor, MI, 1991.

12. Lovins, A.B., J.W. Barnett, and L.H. Lovins. Supercars: the Coming Light-Vehicle Revolution. Rocky Mountain Institute, Snowmass, CO, 1993.

13. Murrell, J.D., K.H. Hellman, and R.M. Heavenrich. Light-Duty Automotive Technology and Fuel Economy Trends through 1993. Report EPA/AA/TDG/93-01, U.S. Environmental Protection Agency, Ann Arbor, MI, 1993.

14. An, F., and M. Ross. A model of fuel economy and driving patterns. SAE Paper No. 930328, Society of Automotive Engineers, Warrendale, PA, 1993.

15. Ross, M. Automobile fuel consumption and emissions: effects of vehicle and driving characteristics. Annual Review of Energy and Environment, 19:75-112, 1994.

16. DeLuchi, M.A., Q. Wang, and D.L. Greene. Motor vehicle fuel economy: the forgotten HC control strategy? Report ORNL-6715, Oak Ridge National Laboratory, Oak Ridge, TN, June 1992.

Table 1. Fuel Economy Cost and Benefit Estimates by Technology

\begin{tabular}{lcccc} 
TECHNOLOGIES & $\begin{array}{c}\text { RETAIL COST } \\
(1990 \$)\end{array}$ & Level 1 & $\begin{array}{c}\text { MPG BENEFIT } \\
\text { Level 2 }\end{array}$ & Level 3 \\
\hline \hline ENGINE & & & & \\
Multipoint fuel injection & 75 & $3.0 \%$ & $3.0 \%$ & $3.0 \%$ \\
Four valves per cylinder & 110 & $6.6 \%$ & $6.6 \%$ & $6.6 \%$ \\
Friction reduction & 100 & $6.0 \%$ & $6.0 \%$ & $6.0 \%$ \\
Overhead camshaft & 40 & $3.0 \%$ & $3.0 \%$ & $3.0 \%$ \\
Compression ratio increase & 0 & $1.0 \%$ & $1.0 \%$ & $1.0 \%$ \\
Variable Valve Control & 130 & $12.0 \%$ & $12.0 \%$ & $12.0 \%$ \\
Super- or Turbocharging & 160 & $5.0 \%$ & $5.0 \%$ & $8.0 \%$ \\
Variable displacement & 65 & 0 & $5.0 \%$ & $5.0 \%$ \\
Idle off & 260 & 0 & $6.0 \%$ & $6.0 \%$ \\
Lean burn or Two stroke & 75 & 0 & 0 & $10.0 \%$ \\
TRANSMISSION & & & & \\
Five-speed automatic transmission & 110 & $5.0 \%$ & $5.0 \%$ & $5.0 \%$ \\
Continuously variable transmission & 30 & $6.0 \%$ & $6.0 \%$ & $6.0 \%$ \\
Torque converter lockup & 55 & $3.0 \%$ & $3.0 \%$ & $3.0 \%$ \\
Optimized transmission control & 60 & $0.5 \%$ & $9.0 \%$ & $9.0 \%$ \\
Optimized manual transmission & 60 & $11.0 \%$ & $11.0 \%$ & $11.0 \%$ \\
LOAD & & & & $4.0 \%$ \\
Lower rolling resistance tires & 20 & $3.4 \%$ & $4.8 \%$ & $6.1 \%$ \\
Aerodynamic improvements & 90 & $3.3 \%$ & $3.8 \%$ & $4.3 \%$ \\
Weight reduction & 150 & $3.9 \%$ & $9.9 \%$ & $15.9 \%$ \\
Accessory improvements & 13 & $1.7 \%$ & $1.7 \%$ & $1.7 \%$ \\
Lubricant improvements & 2 & $0.5 \%$ & $0.5 \%$ & $0.5 \%$ \\
\hline
\end{tabular}

Based on Tables 1 and 4 of reference (1). Costs are estimated retail price increments. Benefits are for each technology as applied to a typical individual vehicle, listed by technical certainty level. 
Table 2. Fuel Energy Use by a 1991 Ford Taurus and Potential Reductions using Technologies for Efficiency

\begin{tabular}{|c|c|c|c|c|c|}
\hline \multirow[b]{2}{*}{ ENERGY SINK } & \multicolumn{2}{|c|}{1991 base vehicle } & \multirow{2}{*}{$\begin{array}{l}\text { Reduction } \\
\text { factor }\end{array}$} & \multicolumn{2}{|c|}{ Improved vehicle } \\
\hline & $\mathrm{kJ} / \mathbf{k m}$ & $\%$ & & $\mathrm{~kJ} / \mathbf{k m}$ & $\%$ \\
\hline Tire rolling resistance & 405 & 15 & $(0.68)(0.85)$ & 234 & 15 \\
\hline Aerodynamic drag & 378 & 14 & $(0.82)$ & 310 & 19 \\
\hline Braking & 361 & 13 & $(0.85)$ & 306 & 19 \\
\hline Accessories & 150 & 5 & $(0.70)$ & 106 & 7 \\
\hline \multirow{2}{*}{$\begin{array}{l}\text { Subtotal, vehicle loads } \\
\text { effect of } 2.5 \% \text { CR increase: }\end{array}$} & 1294 & 46 & {$[0.739]$} & 956 & \\
\hline & & & $(0.975)$ & 932 & 59 \\
\hline \multirow{2}{*}{$\begin{array}{l}\text { Engine friction, powered } \\
\text { Engine friction, idling }\end{array}$} & 1159 & 42 & $(0.53)(0.83)$ & 510 & 32 \\
\hline & 330 & 12 & $(0.53)(0.83)$ & 145 & 9 \\
\hline Subtotal, engine friction & 1489 & 54 & {$[0.440]$} & 655 & 41 \\
\hline \multirow{2}{*}{$\begin{array}{l}\text { TOTAL ENERGY USE } \\
\text { FUEL ECONOMY (MPG) }\end{array}$} & \multirow{2}{*}{\multicolumn{2}{|c|}{$26.9^{100}$}} & & \multirow{2}{*}{\multicolumn{2}{|c|}{47.2}} \\
\hline & & & {$[1.754]$} & & \\
\hline
\end{tabular}

Table 3. Technical Potential for Improving New Car Fleet Average Fuel Economy

\begin{tabular}{lcccccr}
\multicolumn{1}{c}{$\begin{array}{c}\text { Utilization Level: } \\
\text { Certainty Level: }\end{array}$} & L1 & L2 & L3 & L1 & L2 & L3 \\
\hline \hline ENGINE & $22.5 \%$ & $27.5 \%$ & $35.3 \%$ & $29.6 \%$ & $34.6 \%$ & $42.9 \%$ \\
TRANSMISSION & $6.6 \%$ & $12.3 \%$ & $12.3 \%$ & $7.1 \%$ & $13.9 \%$ & $13.9 \%$ \\
LOAD REDUCTION & $12.5 \%$ & $20.4 \%$ & $28.2 \%$ & $12.8 \%$ & $20.7 \%$ & $28.5 \%$ \\
\hline TOTAL: & $41.6 \%$ & $60.2 \%$ & $75.8 \%$ & $49.5 \%$ & $69.2 \%$ & $85.3 \%$ \\
OPTIMAL TOTAL: & $45.2 \%$ & $68.3 \%$ & $89.2 \%$ & $54.2 \%$ & $79.3 \%$ & $101.5 \%$ \\
POTENTIAL MPG: & 40.4 & 46.8 & 52.6 & 42.9 & 49.8 & 56.0 \\
\hline \hline
\end{tabular}

Percent fuel economy improvements are relative to the base year (1990) new car fleet average of $27.8 \mathrm{mpg}$.
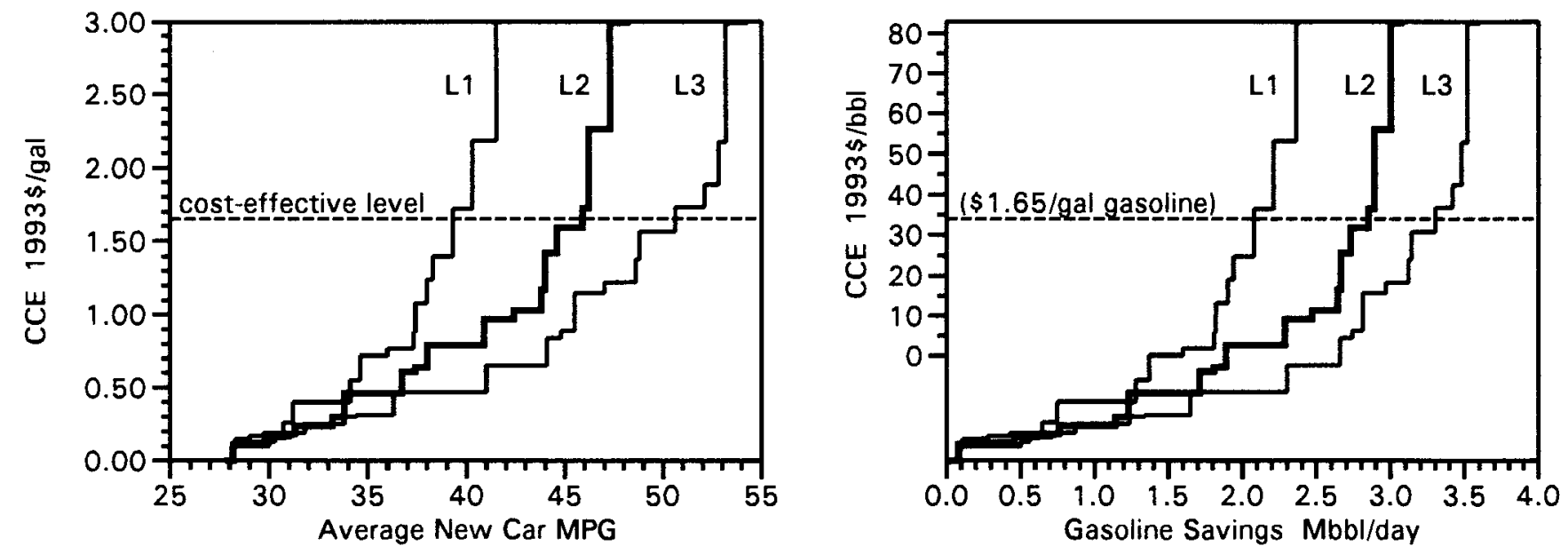

Figure 1. Cost Curves for Fuel Economy Improvement and Gasoline Savings

Left (a): Cost of Conserved Energy (CCE) vs. new car fleet average MPG (EPA unadjusted city/highway composite cycle). Right (b): CCE vs. nationwide U.S. gasoline savings in 2010, assuming fuel economy improves linearly over 1996-2005 to the steps as shown in (a), proportionate improvements for both cars and light trucks, $20 \%$ shortfall, and a $10 \%$ rebound effect. Curves for each technology certainty level (L1-L3) are based on an average of High and Full technology utilization levels. $\mathrm{CCE}$ is based on a $5 \%$ real discount rate over a 12 -year, 10,000 mile/year vehicle life. 